\title{
A condição humana de Hannah Arendt e os equívocos na interpretação de Byung- Chul Han
}

\section{The human condition of Hannah Arendt and the misunderstandings in Byung-Chul Han's interpretation}

\author{
Judikael Castelo Branco e \\ Professor de filosofia da UFT \\ Lara França da Rocha \\ Doutoranda em filosofia pela UFC
}

Resumo: Neste artigo apresentamos algumas noções fundamentais de $A$ condição humana para nos confrontarmos com a interpretação de Byung-Chul Han. Para tanto, nos concentramos na problemática posta pelo filósofo sul-coreano ao perguntar se o animal laborans de Arendt resiste à análise das evoluções sociais recentes da "sociedade do cansaço", o que, a nosso ver, não apenas evidencia o erro de Han como mostra também a coerência do texto de Arendt, que conclui apontando para as bases da reflexão sobre a "vida do espírito".

Palavras-chave: Política; Modernidade; Condição humana; Ação. 
Abstract: We present in this paper some fundamental notions of The Human Condition to review Byung-Chul Han's interpretation. We are going to focus on the problem posed by the South Korean philosopher, that is, the question if the animal laborans resists the analysis of recent social evolutions of the "burnout society". For us, this procedure shows that Han is wrong, as is also shown by the coherence of Arendt's text, which she concludes by pointing to the basis of reflection of the "life of the mind".

Keywords: Politics; Modernity; Human Condition; Action.

\section{Introdução}

$\mathbf{E}$ ste artigo apresenta elementos essenciais do pensamento análise da situação do indivíduo e da sociedade na modernidade. Porém, esse objetivo imediato é acompanhado por um mais restrito, isto é, a leitura dos equívocos de Byung-Chul Han na interpretação da última parte da obra de Arendt.

Já o prólogo de A condição humana situa o escrito num momento histórico específico, mais precisamente, a autora o coloca no contexto marcado pela chegada do homem à lua e pelo processo irrefreável de automação da atividade humana (cf. Arendt, 2014a, p. 1-7). O primeiro, algo que, para nós, já parece parte de um passado relativamente distante, o outro, uma marca fortemente presente, mas cuja possibilidade de superação pelas conquistas da hipertecnologia se mostra todos os dias mais sentida. Contudo, apesar da estreita relação entre o escrito e o seu momento histórico, continuamos a ler a obra arendtiana passadas mais de seis décadas da sua publicação. Disso, uma primeira consideração já se impõe, a pergunta pela atualidade da reflexão de Arendt, uma questão que as impressões e reimpressões da obra, bem como a multiplicação dos comentários dedicados a ela, não se cansam de responder. ${ }^{36}$

Outro elemento fundamental no pensamento de Arendt é a falta de pretensão de erguer sistemas capazes de antecipar 36 Cf. Heuer e Liebel, 2017, p. 500-503. 
o sentido de eventos políticos. Desse modo, abre mão de tentar construir códigos prescritivos, antes se ocupa em apontar as perguntas urgentes. Trata-se de assumir postura necessária tanto para a correta avaliação da atual crise política quanto para iluminar esses tempos sombrios (cf. Arendt, 2018).

Ao se concentrar na ação, Arendt compreende a política a partir do que constitui o domínio próprio do agir e do existir humano: a finitude e a historicidade; conjuga a singularização dos seres humanos com a política a fim de evidenciar os sujeitos da ação, e, ao mesmo tempo, iluminar as instituições que devem salvaguardar a faculdade humana de "começar coisas novas". Essa abordagem se torna cada vez mais importante num "mundo mecânico", porquanto visa à recuperação da política como o espaço da iniciativa e da participação pública. ${ }^{37}$

Para o que nos ocupa, partimos da concepção da filosofia política como reflexão sobre a ação para compreender o pensamento de Arendt como um todo e A condição humana em particular. Com efeito, no conjunto da sua obra, o livro de 1958 acompanha tanto $O$ conceito de amor em Santo Agostinho, de 1929, como Origens do Totalitarismo, de 1951, compartilhando com esses algumas das principais marcas do seu pensamento político, como, por exemplo, as reflexões sobre o homem como ser agente, sobre as condições da ação e acerca do mal que pode surgir quando o agir se perverte em fabricação.

Em A Condição humana, seguindo o método da "análise conceitual", trata da relação entre modernidade e política e das suas repercussões sobre a vida humana. ${ }^{38}$ Argumenta em torno da análise das atividades formadoras do âmbito da vita activa a partir da sua contraposição à vita contemplativa. Em princípio, rearticula a vida activa em seu múltiplo desdobramento interno, num exercício que repousa sobre a afirmação da definição das atividades humanas fundamentais à luz do primado da ação.

\footnotetext{
$37 \quad$ Cf. Duarte, 2001.

38 Sobre a especificidade da expressão "análise conceitual" para definir o método de Arendt, cf. Young-Bruehl, 1997, p. 286. Para uma visão abrangente do método arendtiano, ver o artigo de André Duarte (2013).
} 
Para alcançar os objetivos que nos propomos, apresentamos alguns elementos essenciais da obra de Arendt, depois destacamos o conceito de progresso para a sua análise da mentalidade do homem moderno; em seguida, expomos a impossibilidade da ação na sociedade do desempenho de Han e, por fim, a sua crítica à obra $A$ condição humana, sublinhando os pontos nos quais, a nosso ver, o autor se equivoca.

\section{O primado da ação}

Para a Arendt, o primado da ação se justifica pela sua constitutiva correspondência aos conceitos de pluralidade e de natalidade. Com efeito, entre as atividades humanas, a ação é a única que de fato se coloca diretamente entre os homens, correspondendo, assim, à condição da "paradoxal pluralidade de seres únicos" (Arendt, 2014a, p. 220); pluralidade que - entendida como o "fato de que os homens, e não o Homem, vivem na Terra e habitam o mundo" - se define como a verdadeira "lei da Terra" (Arendt, 2009, p. 35). Logo, se a ação depende da pluralidade, ela também a reforça, pois só pela ação o indivíduo confirma sua singularidade e aparece a outros indivíduos.

Da mesma forma, é a atividade mais estreitamente ligada à natalidade, conceito imprescindível à compreensão da obra arendtiana como um dos distintivos do seu pensamento. Para reconhecer a sua originalidade, basta contrapô-lo à proposta das primeiras obras de Heidegger, nas quais o autor pauta o agir decisivo do homem na morte. Arendt, ao contrário, ao ligar a reflexão sobre a ação ao nascimento, concede a esse conceito a ênfase de um novo começo, pois "[um novo início] pode fazer-se sentir no mundo somente porque o recém-chegado possui a capacidade de iniciar algo novo, isto é, de agir" (Arendt, 2012, p. 10). ${ }^{39}$ Por isso, para Arendt, não é a mortalidade que norteia a política, mas o fato de que os homens "não nasceram para morrer, mas para começar" (Arendt, 2016, p. 305). Desse modo, é possível compreender que o evento inaugural,

39 Existe uma extensa bibliografia sobre a possibilidade de novos começos como faculdade constitutiva do homem em Arendt, aqui, indicamos Müller, 2018. 
que possibilita que outros inícios sejam empreendidos, coincide com o nascimento de cada homem. Este acontecimento, que literalmente inaugura todos os outros começos, é também reafirmado sempre que os indivíduos "iniciam novos processos a partir de si mesmos" (Arendt, 2006, p. 67).

Mas, pelo nascimento, o homem é apenas inserido na Terra, enquanto a sua entrada no mundo humano só ocorre de fato através de palavras e ações. ${ }^{40}$ Como Arendt (2014a, p. 221) assevera, essa inserção "é como um 'segundo nascimento', no qual confirmamos e assumimos o fato simples de nosso aparecimento físico original". O primeiro nascimento coloca o homem - naturalmente - como um ser num mundo dado de antemão, ou seja, faz do homem um ser do mundo. Por sua vez, a inserção no mundo humano não se impõe por necessidade ou utilidade, mas é "estimulada pela presença de outros a cuja companhia possamos desejar nos juntar, mas nunca é condicionada por eles; seu impulso surge do começo que veio ao mundo quando nascemos e ao qual respondemos quando começamos algo novo por nossa própria iniciativa" (Arendt, 2014a, p. 221).

O que está em jogo no que concerne à justa compreensão da capacidade de agir é, de um lado, a compreensão da sua relação essencial com a realidade do espaço de aparência e a fundação de corpos políticos duradouros como condições de possibilidade do que podemos chamar de "felicidade pública". Esta está assentada no direito de participação da esfera pública, isto é, de uma forma de felicidade cuja raiz é a própria noção política de liberdade (cf. Arendt, 2016, p. 172-173). Em outros

\footnotetext{
$40 \quad$ Vale destacar a diferenciação empreendida pela autora entre o mundo construído a partir da obra do homo faber e o mundo que separa e une os homens todas as vezes que eles se encontram para agir e discutir sobre aquilo que os inter-esa. O primeiro é fruto do artifício e da engenhosidade dos homens, ganham existência primeiro através do pensamento e da imaginação humana e fornecem maior durabilidade para o mundo, já que seus produtos não são consumidos, mas utilizados. O mundo humano, no entanto, surge potencialmente quando os homens se encontram em ação e em discurso, um espaço intermediário que congrega e separa sem fazê-los colidir. É dialogando com esta última perspectiva que a autora constrói sua teoria política.
} 
termos, para Arendt, a ação denota que os homens não podem estar satisfeitos, de fato, encerrados em sua vida privada. ${ }^{41}$

Postos alguns elementos essenciais à compreensão do pensamento arendtiano, podemos passar à consideração de uma das questões fundamentais de $A$ condição humana. ${ }^{42}$ Nessa obra, Arendt toma a sociedade moderna como aquela na qual se tornou possível pensar o aniquilamento do agir, uma possibilidade real por causa do esvaziamento do mundo comum e da degradação do homem à condição de animal laborans - um animal trabalhador. De um lado, enquanto o agir se caracteriza essencialmente por instaurar novos começos, o homem moderno se encontra passivamente exposto ao processo anônimo da vida, no qual todas as formas de vita activa decaem ao patamar do trabalho. De outro lado, o próprio pensamento degenera à mera função cerebral, isto é, decai à condição de "cálculo de consequências" (Arendt, 2014a, p. 402). Em suma, Arendt percebe a contradição inerente à era moderna que se iniciou com a promessa de realização das possibilidades do homem, mas findou por levá-lo a uma condição de passividade mortal. Por seu turno, nesse horizonte, a sociedade moderna se fez como esfera híbrida entre o público e o privado, esfera cuja lógica pode degenerar tanto as condições do agir quanto as do pensar. ${ }^{43}$

No que concerne ao homem moderno, devemos dizer também que a sua vida está "submersa no processo vital da espécie e a única decisão ativa do indivíduo [é] deixar-se levar, (...) abandonar a sua individualidade, (...) e aquiescer a um tipo funcional, entorpecido e 'tranquilizado' de comporta-

\footnotetext{
$41 \quad$ A partir de uma perspectiva alternativa, a questão é tratada em Castelo Branco (2018).

42 Para uma visão mais ampla, ver o texto de Hurtado (2013), que sublinha a posição de Arendt diante do pensamento moderno ao optar pela superação de uma perspectiva centrada exclusivamente no sujeito deslocando-se na direção da pluralidade. Ademais, no que concerne ao pensamento de Arendt como um todo, o seu caráter crítico e experiencial, ver Leibovici (1998) e Genel (2016).

43 É indispensável aqui mencionar a diferenciação feita pela autora, no Prólogo de A Condição Humana, sobre era moderna e mundo moderno. Enquanto o último se iniciou com as explosões atômicas, a primeira começou no século XVII e terminou no limiar do século XX (Cf. ARENDT, 2014a, p. 7).
} 
mento" (Arendt, 2014a, p. 403). Em outros termos, ele deve abandonar a própria individualidade para "funcionar melhor". Nota-se aqui a substituição da ação pelo mero comportamento, pelo condicionamento do homem, fruto do advento da sociedade e da vitória do animal laborans. A absolutização do trabalho caminha juntamente com uma forma de evolução segundo a qual a vida da espécie humana se impõe como o único absoluto para a sociedade. Arendt vai ainda mais longe e denota nisso sinais do "perigo de que o homem possa estar disposto e realmente esteja a ponto de converter-se naquela espécie animal da qual, desde Darwin, ele imagina descender" (Arendt, 2014a, p. 403), admitindo, ao fim e ao cabo, que todas as atividades humanas, "vistas de um ponto de observação suficientemente remoto no universo apareceriam não como atividades, mas como processos [biológicos]" (Arendt, 2014a, p. 403). Ao se voltar exclusivamente para a sobrevivência, o trabalho se relaciona com o imediatismo inerente ao ciclo biológico. De fato, a lógica da produção-consumo não permite nem o tempo e nem o espaço de aparência necessários para que os homens se encontrem e construam, em comum acordo, o mundo e a política.

A partir da análise dos vínculos entre as condições das "atividades humanas fundamentais" com a vida política, Arendt pensa a modernidade, expondo as reversões nos desdobramentos internos da vita activa, pela vitória do animal laborans, quer dizer, da conversão da manutenção da vida biológica em bem supremo e o consequente ocaso da política.

\section{Da contemplação do ser ao conhecimento do processo}

Podemos dizer que, de um modo geral, a entrada na modernidade corresponde à passagem a um quadro referencial teórico e prático no qual conhecer é antes de tudo dominar as diferentes partes de um dado particular. ${ }^{44} \mathrm{As}$ implicações dessa

$44 \quad$ É importante ressaltar que aqui não se trata meramente do indivíduo particularizado, mas principalmente do sujeito de conhecimento que, a partir de Descartes, era composto pela res extensa e pela res cogitans, esta última enquanto o aparato cognitivo universal e estruturador de toda experiência de objetos. Nesses termos, o pensamento é tomado como pura atividade cerebral, o raciocínio envolto em si mesmo, preso apenas ao próprio 
passagem podem ser vistas tanto no fato de que "a contemplação mesma tornou-se completamente sem sentido", quanto na condição moderna do pensar como "servo do agir" (Arendt, 2014a, p. 364), prerrogativa indispensável para o desenvolvimento das ciências. Portanto, o próprio pensamento foi sujeitado ao raciocínio lógico e científico, colocado numa posição análoga à da filosofia medieval, antiga ancilla theologiae. A diferença está no fato de que se nesse quadro antigo a filosofia, por exemplo, se orientava fundamentalmente a partir da contemplação, imo da ciência teológica, ao passo que agora, todo conhecimento passa a ser regido também por outros princípios além daquele clássico, a saber, a necessidade. O que está em jogo é também o auxílio que a ciência moderna foi angariar no homo faber para adquirir conhecimento, tendo o propósito teórico de realizar certos experimentos com a natureza.

Sobre o modo como compreende a transformação promovida pela revolução científica moderna, Arendt ressalta que o desenvolvimento da ciência não deve ser compreendido pela sua aplicabilidade, ou através do mero desejo pragmático de melhorar as condições da vida humana na Terra. Ao contrário, deve-se entender que por mais que a fabricação de instrumentos que levou à moderna revolução científica atrelou o desenvolvimento da ciência ao progresso de instrumentos e de aparelhagens experimentais, isso não significa que a racionalidade técnico-científica seja uma simples evolução das ferramentas do homo faber. Com efeito, o que esteve em jogo no advento da ciência moderna não foi o caráter simplesmente "prático" e "instrumental" do fazer e do fabricar, mas sim o auxílio que a ciência moderna significou para as capacidades produtivas do fazer e do fabricar, bem como para adquirir conhecimento, tendo o propósito altamente 'teórico' de realizar certos experimentos com a natureza, ou seja, pelo motivo 'teórico' de que a certeza do conhecimento não podia ser obtida de outra forma. Não foram os "instintos práticos dos homens" que fizeram surgir

movimento interno. Vinculado ao mundo apenas através dos objetos apreendidos sensorialmente, o sentido de realidade é compreendido como universal apenas porque todos os indivíduos o possuem, e não porque disponham de vínculos entre si. Cf. ARENDT, H. 2014a p. 307-403. 
a revolução científica moderna. Como diz: "é pouco provável que nosso mundo condicionado à técnica pudesse sobreviver, e muito menos continuar a desenvolver-se, se conseguíssemos nos convencer de que o homem é, antes de tudo, um ser prático" (2014a, p. 361). Arendt apresenta uma leitura peculiar, se não do processo que descreve, ao menos dos elementos escolhidos para descrevê-lo. Com efeito, ela sublinha a mudança de paradigma na modernidade a partir das reversões internas no âmbito das atividades humanas. Parte-se do que está absolutamente estabelecido, quer dizer, da saída do quadro emoldurado pela ideia de um cosmo harmonioso a servir como ideal à vida do homem e à sociedade, do mesmo modo que se sai do quadro cristão, assemelhado àquele, mas pondo como categoria central da explicação da realidade e, deste modo, também da ação humana, a noção de Providência divina. De um modo geral, podemos definir essa passagem como o abandono de qualquer concepção de absoluto transcendente, passagem importante, porém não exclusiva, para se entender o lugar do animal laborans no mundo moderno..$^{45}$

Mas, a condição do animal trabalhador é precedida histórica e teoricamente pela primazia da fabricação, o que equivale a dizer, pela vitória do homo faber. Na prática, trata-se da mudança na qual "a natureza [...] tornou-se um processo, e o significado e a importância de todas as coisas naturais particulares decorriam unicamente das funções que elas exerciam no processo global" (Arendt, 2014a, p. 370). Em última instância, o homem troca o absoluto cósmico ou divino pelas condições da terra a serem conhecidas pelas ciências, e "no lugar do conceito do Ser, encontramos agora o conceito de Processo" (Arendt, 2014a, p. 370).

Essa reversão provoca a reavaliação de todas as esferas da realidade, inclusive a que concerne ao sentido da ação do homem sobre o mundo. Em outros termos, no que tange ao trabalho e à fabricação, afirmar que a noção de processo assume o lugar que no passado foi ocupado pelo Ser ou por Deus, confirma também que, na modernidade, o próprio processo inerente 45 Sobre a definição arendtiana de animal laborans, ver o texto de Adriano Correia, 2013. 
ao trabalho se torna, em muitos aspectos, mais importante do que o seu resultado. "É da natureza do Processo permanecer invisível, ser algo cuja existência pode apenas ser inferida da presença de certos fenômenos. Esse processo foi originariamente $o$ processo de fabricação, que 'desaparece no produto', e baseouse na experiência do homo faber, que sabia que um processo de produção precede necessariamente a existência efetiva de todo objeto" (Arendt, 2014a, p. 371). Em última instância, o mundo se torna um mecanismo e relacionar-se com ele lembra muito pouco o gesto antigo de contemplá-lo. Antes, nessa "visão mecanicista do mundo" (Arendt, 2014a, p. 371), todos os fenômenos se tornam partes de uma engrenagem numa sequência ininterrupta de causa e efeito que dá à natureza, e ao próprio homem, seu caráter processual definitivo.

Porquanto reconstrói os momentos formadores do âmbito moderno da vita activa, Arendt evoca o caráter fundamental da natureza da mudança no campo prático, pois é ela que ocasiona as transformações teóricas características da modernidade. De certo modo, isso corresponde à postura peculiar da autora de pensar a vita activa a partir das suas próprias transformações internas e não da perspectiva da vita contemplativa ou da linguagem teorética. É no campo prático que a mudança se opera, pois é no terreno das atividades humanas fundamentais que se dá, de forma definitiva, "o rompimento com a contemplação", ou seja, a "introdução do conceito de processo na atividade da produção" (Arendt, 2014a, p. 376).

Vem à baila com essa mudança o perigo real de se "perder o mundo", ou seja, a verdadeira possibilidade da quebra do elo com o quadro referencial teórico e prático já conhecido para o pensar e para o agir. Por decorrência, sem princípios suficientes para nortear as ações humanas, sobram-nos apenas duas formas para compreender esse novo universo paradigmático, lembrando que nele "o homo faber foi privado daquelas medidas permanentes que precedem e sobrevivem ao processo de fabricação e que constituem um absoluto confiável e autêntico em relação à atividade da fabricação" (Arendt, 2014a, p. 384). De um lado, dispomos da via que se ocupa 
com o conhecimento, com os padrões procedimentais das ciências experimentais modernas e de seu modelo epistemológico, cujo centro se coloca, precisamente, na base formada pela física como imagem ideal de toda ciência, a linguagem matemática e o método da observação. De outro lado, porém, temos também a introspecção, quer dizer, a abertura para a filosofia da consciência, entendida como sentido interior com o qual o indivíduo "sente os seus sentidos". Com efeito, para essa nova forma de filosofar, a consciência é "a única segurança da realidade" - e continua - "agora, o filósofo já não se volta de um mundo de enganosa perecibilidade para outro mundo de verdade eterna, mas volta as costas a ambos e se retira para dentro de si mesmo (Arendt, 2014a, p. 366). Como Arendt afirmará depois (2014a, p. 383-384):

Para a mentalidade do homem moderno, determinada pelo desenvolvimento da ciência moderna e pelo concomitante desabrochar da moderna filosofia, era pelo menos igualmente decisivo que o homem passasse a se considerar parte integrante dos dois processos sobre-humanos e oniabrangentes da natureza e da história, ambos aparentemente condenados a progredir infinitamente sem jamais alcançar qualquer telos inerente ou aproximar-se de qualquer ideia predeterminada.

É o cenário que culmina com a perda do mundo, entendida em Arendt como a inviabilização da existência deste espaço potencial que congrega e separa os indivíduos ${ }^{46}$, e com a mudança radical das perspectivas filosóficas, a princípio exclusivamente orientadas ou a questões epistemológicas ou a problemas de fundamentação moral. Finalmente, as "prerrogativas do homo faber" (Arendt, 2014a, p. 368) se elevam à posição mais destacada entre as atividades humanas fundamentais, o que equivale a dizer que "a produtividade e a criatividade, que iriam tornarse os mais altos ideais e inclusive os ídolos da era moderna em seus estágios iniciais, são emblemas inerentes do homo faber, ao homem como construtor e fabricante" (Arendt, 2014a, p. 370).

$46 \quad$ Para a autora, a mais radical experiência que um indivíduo pode ter é a sensação de não-pertencimento ao mundo. Com efeito, a perda do mundo, possibilitada pelo isolamento e pela alienação, culmina com a formação de uma sociedade de indivíduos sem rosto, massificada e que abriga em si o germe para a fundação de regimes antipolíticos. Sobre a perda do mundo, cf. ARENDT, 2011a, p. 527. 
Mas, para Arendt, estamos apenas na metade do caminho, pois o "processo" se torna também a chave para a ação política. Não podemos negar que a técnica moderna fez do nosso mundo o que ele é e que nossa cultura é moldada e reformada a todo instante pela ciência e pela tecnologia. Isso implica também que as prerrogativas do homo faber gradualmente se tornaram "princípio para o agir no domínio dos assuntos humanos" (Arendt, 2014a, p. 374). Se "os processos, portanto, e não as ideias, os modelos e as formas das coisas a serem criadas, tornam-se na era moderna os guias das atividades de produzir e de fabricar" (Arendt, 2014a, p. 375), essas mudanças não poupam o campo política.

Sobre isso, basta recordar que o risco da redução da política à questão técnica é um fato, e o papel da administração nesse campo constantemente o comprova. Hoje, cada vez mais os problemas coletivos se tornam problemas de detalhamento técnico, reservados a conhecimentos especializados e linguagens que excluem a grande maioria dos envolvidos. Um exemplo do extremo alcançado pela racionalização da vida pública é a consolidação da burocracia como forma de administração que, sem prestar conta de seus atos, impossibilita a felicidade pública própria à ação e à liberdade. Na burocracia, no domínio de ninguém, uma tirania sem tirano, os funcionários são incentivados a cumprir ordens e a cultivar o empreendedorismo, contanto que este se mova sempre dentro dos limites propostos pelas normas institucionais. Com efeito, o pensamento como uma atividade essencialmente dialógica é impossibilitado num regime em que a solidão é a experiência predominante dos homens.

Porquanto nos vemos impossibilitados da ação no plano público, resta-nos apenas o espaço privado, aquele próprio do trabalho em função da manutenção da vida. Para Arendt, porém, esse espaço está contraposto ao público numa relação de mútua exclusão. Surge daí o terreno propício tanto à atividade antipolítica do animal laborans, profundamente marcada por sua condição de isolamento, quanto o domínio em que o homo faber desenvolve a fabricação atividade que mantém, de certa forma, relações essenciais com o mundo humano, mas sempre como atividade apolítica. Aí reside um dos aspectos que mais 
diferenciam trabalho e fabricação. Enquanto do isolamento da fabricação advêm objetos e ferramentas que compõem o mundo artificial humano, ainda suficiente para fundar o mundo entre os homens, a loneliness do animal laborans não se vincula de modo algum com o mundo. Por isso, qualquer organização baseada no trabalho está fadada a degenerar a política e a substituir a ação pelo comportamento calculável e padronizado.

A análise nos leva à sociedade moderna como cenário no qual é impossível a ação política justamente por causa do isolamento dos indivíduos no trabalho, pela ausência do outro e, consequentemente, pela perda do mundo. Sem o outro e sem o mundo, o indivíduo que se perde, esvaziando a noção de ser individual, por não poder mais aparecer àquele que o reconheceria como tal. Ademais, não podemos esquecer que o um é sempre impotente frente aos demais. O trabalhador de hoje é, usando as palavras de Eric Weil, o "escravo moderno" (Weil, 1996, p. 330), aquele que não distingue quem o educa de quem o subjuga, pois pensa se libertar através do trabalho, sem compreender o que está em jogo de fato.

A pergunta que podemos nos fazer agora é se essa condição mudou, e, em caso afirmativo, em que sentido mudou nos últimos 60 anos. Arendt descreve a condição humana na segunda metade da década de 50, impressionada pelas novas conquistas científicas e espaciais, que curiosamente abrem um livro de análise conceitual. Continuamos pensando as condições do nosso tempo. No caso do filósofo Byung-Chul Han, trata-se de pensar a sociedade de "superprodução, superdesempenho, superconsumo, supercomunicação e superinformação" (Han, 2017a, p. 190). Ao fazê-lo, ele analisa partes de A condição humana de Arendt, a nosso ver, porém, na sua interpretação, se equivoca em mais de um ponto.

\section{A im-possibilidade da ação política na sociedade do desempenho}

Na obra de Byung-Chul Han, a sociedade moderna é abordada a partir da sua "positividade ocidental" (Han, 2017a, p. 216). Trata-se da tentativa de compreender o proces- 
so no qual "sociedade da negatividade dá espaço a uma sociedade na qual vai se descontruindo cada vez mais a negatividade em favor da positividade" (Han, 2017b, p. 9). Essa mudança de paradigma não se limita ao âmbito político ou social, pois se estende a todas as esferas constitutivas da vida humana, inclusive às relações de amor (cf. Han, 2017c, p. 29). Temos, então, de compreender uma sociedade que se caracteriza, em última instância, pelo "excesso de positividade" (Han, 2017d, p. 8), isto é, por uma forma própria de "violência" que "se manifesta como exagero e desproporção, como excesso, exuberância, exaustão e como superprodução, superacumulação, supercomunicação e superinformação" (Han, 2017a, p. 169).

No que concerne ao nosso tema, cabe-nos descrever as condições do sujeito numa sociedade da positividade, bem como analisar o que talvez seja o ponto mais exigente para o confronto entre as obras de Arendt e de Han: o papel do outro, ou, se preferirmos, a noção de "alteridade".

Antes de tudo, é fundamental observar que a uma sociedade de positividade marcada fundamentalmente pelo excesso, só pode corresponder o "sujeito de desempenho e produção" (Han, 2017d, p. 23). De certa forma, estamos, segundo Han, no momento de saturação da sociedade que se ordena em função do trabalho organizado, como definido por Max Weber. No entanto, é possível que a reflexão nem sempre alcance a extensão do que significa esse estágio e, por isso, Han não se limita a fazer referência às gaiolas de cimento weberianas, antes fala de um mundo reduzido à máquina (cf. Han, 2017b, p. 12). Neste, não resta ao sujeito senão identificar-se com a engrenagem de um mecanismo.

Vamos nos limitar aqui à análise de dois elementos fundamentais dessa moldura. Por um lado, é preciso compreender a situação do sujeito entre a "luta consigo mesmo" (Han, 2017d, p. 29) e o risco do "tédio profundo" (Han, 2017d, p. 33). Por outro lado, deve-se considerar os traços da sociedade da positividade no domínio político ou, dito de outra forma, pensar o contexto "pós-político" (Han, 2017b, p. 23), no qual a política se reduz à mera "ação estratégica" (Han, 2017a, p. 206; 2017b, p. 21). 
A situação do sujeito de desempenho se distingue daquela do sujeito da sociedade da negatividade, repressiva ${ }^{47}$, porquanto, hoje, o indivíduo explora a si mesmo. A passagem da exploração para a autoexploração se dá a partir do momento em que o sujeito de desempenho se compreende dentro da lógica da sociedade de produção. Com efeito, se nessa lógica o mundo se torna um mecanismo opaco, a sociedade e o homem se tornam "máquinas de desempenho autistas" (Han, 2017d, p. 56).

Han se mantém nos limites da descrição da situação desse sujeito, quer dizer, sequer aponta saídas possíveis à passagem do "trabalho" à "ação" (para usarmos mais uma vez as palavras de Arendt). O que aponta com firmeza é que nessa "sociedade do excesso" não há verdadeira liberdade, pois "ela acaba gerando novas coerções. É uma ilusão acreditar que quanto mais ativos nos tornamos tanto mais livres seríamos" (Han, 2017d, p. 52). A única forma de liberdade que ela conhece é a ausência de impedimentos à colaboração no mecanismo do trabalho organizado e o que ela tem de mais pernicioso seja talvez a capacidade de identificar essa concepção tão restrita com a liberdade enquanto tal.

No quadro descrito por Han, o sujeito explorado da antiga sociedade da negatividade passa à condição do sujeito autoexplorado. Esse aspecto é original da modernidade como elemento essencial à compreensão do sujeito. No entanto, a exposição dá margem a interpretações unilaterais, porquanto a autoexploração convive ainda com a exploração constitutiva da sociedade da negatividade. Han encontra nessa passagem, do sujeito explorado ao indivíduo autoexplorado, o eixo a partir do qual é possível compreender o caráter original da modernidade. Posto desse modo, temos, de um lado, a manutenção da liberdade como a questão constitutiva da modernidade, e, de outro, a percepção de uma nova concepção do termo, pois o sujeito de desempenho se compreende numa condição diferente daquela própria ao sujeito da sociedade da negatividade. É

$47 \quad$ Para Han, um dos principais exemplos da sociedade da negatividade é a psicanálise freudiana, cujo aparato é, ele mesmo, um "sistema da negatividade". Sobre isso, cf. Han, 2017a, p. 51-82. 
o que o autor sublinha ao dizer que "o sujeito do desempenho é livre, na medida em que não está submisso a outras pessoas que lhe dão ordens e o exploram; mas realmente livre ele não é, pois explora a si mesmo e quiçá por decisão pessoal" (Han, 2017c, p. 21). "O sujeito de desempenho é livre pois não está submetido a ninguém" (Han, 2017a, p. 182). Só nesse contexto pode aparecer o que, na visão de Han (2017c, p. 23), se põe como o imperativo paradoxal da nossa sociedade, a nossa obrigação de sermos livres.

A situação do sujeito de desempenho, porém, só pode ser compreendida se considerarmos ainda as novas formas de violência às quais ele está submetido. Essa compreensão exige o que o autor chama de "topologia da violência", um discurso que aponte os novos territórios da violência na sociedade da positividade. É nesse campo que a análise de Han enriquece as discussões acerca da depressão como uma característica comum entre os sujeitos de desempenho, quase todos atingidos pela Síndrome de Burnout. Trata-se, em outros termos, da tarefa de destacar as novas formas de violência imanentes ao sistema da sociedade da positividade (cf. Han, 2017d, p. 19), da sua violência sistêmica, sobretudo como depressão do esgotamento (cf.Han, 2017d, p. 27).

No entanto, a análise de Han extrapola a esfera meramente subjetiva e abre espaço para compreender as implicações políticas da vitória do sujeito de desempenho. Trata-se, fundamentalmente, do "cansaço da sociedade do desempenho" como "um cansaço solitário, que atua individualizando e isolando", quer dizer, daquele que "destrói qualquer comunidade, qualquer proximidade, quaisquer elementos comuns... inclusive a própria linguagem" (Han, 2017d, p. 71). Finalmente, é uma forma de cansaço de esgotamento, "não é um cansaço da potência positiva. Ele nos incapacita de fazer qualquer coisa" (Han, 2017d, p. 76).

Interessa-nos o fato de que esse esgotamento, entendido como uma nova de violência é capaz também dedestruir a linguagem, isto é, de desfazer o espaço público, o mundo compartilhado, e impossibilitar o encontro com o outro. Se- 
gundo Han (2017c, p. 14), esse isolamento corresponde ao "desaparecimento da alteridade", ao "excesso do igual" (Han, 2017d, p. 16), condição que o autor descreve em termos definitivos quando se refere ao "Totalitarismo do igual" (Han, 2017d, p. 15).

Se as filosofias características da sociedade da negatividade, como, por exemplo, o existencialismo sartreano, assumiam sem grandes resistências o outro como inferno, a nossa "sociedade da transparência" é "um abismo infernal (Hölle) do igual" (Han, 2017b, p. 10). O efeito político mais sentido é com certeza a pouca profundidade da comunicação entre iguais, carente da resistência do outro, do estranho que desafia e provoca o pensamento. Numa "sociedade uniformizada" (Han, 2017b, p. 11) não é preciso pensar: "a política dá lugar à violência das necessidades sociais, que deixa intocados os quadros das relações socioeconômicas já existentes, aferrando-se nesse propósito" (Han, 2017b, p. 23). Com efeito, a "erosão do outro" (Han, 2017c, p. 7) só se torna possível em um contexto social específico, isto é, onde o capitalismo elimina a alteridade submetendo tudo ao consumo" (cf. Han, 2017c, p. 35).

Han, ao tratar da erosão do outro, aborda um ordenamento social que abandonou a política, um mundo verdadeiramente pós-político, pois “diante do igual não é possível haver amistosidade nem hostilidade, nem sim nem não, nem saudação nem rechaço" (Han, 2017a, p. 103). A análise do autor se amplia até afirmar que na sociedade do desempenho "não há mais diferença alguma entre classes e sexo" (cf. Han, 2017a, p. 168).

A leitura que o autor faz da nossa sociedade é acertada porquanto salienta seus aspectos específicos, isto é, aponta os elementos que a distinguem de antigas formas de ordenamento social. No entanto, basta retomar a última citação de Han para reconhecer que suas palavras não descrevem toda a nossa sociedade, embora isso não tire nada de seus méritos. A filosofia do sul-coreano parece não perceber justamente as repercussões políticas da passagem que descreve da sociedade da negatividade àquela da positividade. 
A crise atual dos processos democráticos, a superficialidade dos debates, o alto nível da ignorância e de desinteresse por assuntos políticos, não são frutos da "erosão do outro" no "inferno do igual", antes se mostram como desejo de negação do outro. Han descreve um mundo sem as categorias schmittianas da distinção entre amigo e inimigo. Mas devemos nos perguntar: este mundo existe de fato? A radicalização dos discursos políticos e a situação dos imigrantes nos territórios europeu e estadunidense apontam para uma direção contrária à da análise de Han.

Na esteira aberta por Nietzsche e seguida, entre outros, por Arendt, Foucault e Agamben, Han está tratando das implicações da "naturalização do homem", isto é, a descontinuidade propriamente moderna entre vivência e experiência, da fissura que inverte todas as correlações de força, bem como dá aos acontecimentos históricos o mesmo caráter imprevisível e irresistível dos acontecimentos naturais. É essa "naturalização" a base da análise arendtiana em $A$ vida do espírito.

\section{O animal laborans e o sujeito do desempenho: Byung-Chul Han leitor de $A$ condição humana}

Voltando à análise de $A$ condição humana, a noção do "processo" aparece como eixo da primeira reversão característica da modernidade, a saber, a formação do quadro no qual a fabricação se põe no lugar mais alto entre as atividades humanas. Mas essa atividade é suplantada pela vitória do animal laborans. Trata-se de uma segunda e definitiva reversão que possibilitou os eventos políticos (e antipolíticos) testemunhados em tempos recentes (e sombrios). De um lado, "a promoção da atividade do trabalho foi precedida por certos desvios e variações da mentalidade tradicional do homo faber" (Arendt, 2014a, p. 383). De outro, a questão fundamental passa a ser, justamente, saber

por que a derrota do homo faber terminou com a vitória do animal laborans; por que, com a ascensão da vita activa, foi precisamente a atividade do trabalho que veio a ser promovida à mais alta posição entre as capacidades do homem. Por que, na diversidade da condição humana, com suas várias capacidades humanas, foi necessaria- 
mente a vida que predominou sobre todas as outras considerações (Arendt, 2014a, p. 392).

Em outros termos, Arendt se interroga sobre as condições que servem de razão para que o trabalhos e faça como a atividade fundamental do homem moderno.

Para Arendt, o trabalho é a atividade correspondente à manutenção da vida biológica, isto é, o que se faz em vista da satisfação das necessidades vitais. Dessa forma de interação do indivíduo com a natureza não surge nenhum vestígio duradouro, apenas se preserva a vida no eterno ciclo de esgotamento e de regeneração, de produção e de consumo: a vida em seu sentido puramente biológico é, portanto, a condição humana do trabalho. Logo, é mister reconhecer que numa sociedade em que o trabalho se torna a atividade par excellence, a vida naturalmente se converte em bem supremo para o indivíduo e para a sociedade.

Para Arendt, no que concerne ao relato histórico dos elementos que tornam a vida biológica o único sagrado da modernidade, é preciso considerar que "a vitória do animal laborans jamais teria sido completa se o processo de secularização" - como ela descreve - "a moderna perda da fé como decorrência inevitável da dúvida cartesiana, não houvesse despojado a vida individual de sua imortalidade, ou pelo menos da certeza da imortalidade (Arendt, 2014a, p. 400). Em termos definitivos, deve-se recordar, como faz Byung-Chul Han (2017a, p. 44), que "a perda moderna da fé, que não diz respeito apenas a Deus e ao além, mas à própria realidade, torna a vida humana radicalmente transitória".

Nesse contexto, em A vida do espírito, Arendt (2014b, p. 25-26) destaca que as mortes modernas de Deus, da metafísica e da filosofia têm eco político, o que se sente também no aparente esvaziamento do significado do mundo das aparências, palco da existência humana, resultando, logicamente, na questão acerca das condições constituintes do lugar para a construção da vida. ${ }^{48}$

$48 \quad$ Sobre o desenvolvimento desse tema a partir da noção da secularização e da sua relação com a política no pensamento de Arendt, cf. Eccel, 2018, p. 119-136. 
Tendo perdido as noções de Deus, do mundo e de imortalidade, o campo de interesses do homem se reduz drasticamente. Na prática, só resta a "força natural", a força do próprio processo vital, à qual todos estamos sujeitos, cujo escopo é a sobrevivência da espécie animal humana. Nesse contexto, tudo o que não for necessário ao metabolismo da vida comum com a natureza é supérfluo, só pode ser justificado em termos peculiares à vida humana em oposição à vida animal (cf. Arendt, 2014a, p. 402).

A sociedade moderna, segundo Arendt, é acima de tudo a sociedade de trabalhadores, um tipo de ordenamento social no qual não se espera dos indivíduos nada além da repetição automática das próprias funções num mecanismo social cuja única regra é a vida em competição e concorrência. Essa mesma sociedade não seria possível se "a vida individual, realmente houvesse sido submersa no processo vital global da espécie e a única decisão ativa exigida do indivíduo fosse deixar-se levar, por assim dizer, abandonar a sua individualidade, as dores e as penas de viver ainda sentidas individualmente, e aquiescer a um tipo funcional, entorpecido e 'tranquilizado' de comportamento" (Arendt, 2014a, p. 403).

Os efeitos dessa "segunda natureza" sobre o indivíduo podem ser pensados a partir de diferentes registros. Nossa proposta é retomar a leitura de Arendt, confrontando-a com a interpretação de Byung-Chul Han das últimas páginas de $A$ condição humana. Os autores oferecem perspectivas diferentes de um dos problemas fundamentais da filosofia política moderna: o homem e as determinações da sua liberdade. Arendt nos levou, até esse ponto, à sociedade moderna como o tipo de ordenamento social no qual o animal laborans, como não pode deixar de ser, não dispõe das condições para a ação no sentido político. O mesmo se dá em Han, por motivos assemelhados, mas em análises que apontam para outras direções.

A análise de Han não se ocupa com o domínio político, mas com uma reflexão exclusivamente ética, o que fica evidente, por exemplo, quando nega a pertinência, na sua crítica a Agamben, do conceito de soberania. Han toma o homem moderno 
como indivíduo inserido numa "sociedade do desempenho", na qual, pela sua própria lógica interna, a esfera política se esvai inteiramente. Para o nosso argumento, é importante remontar à noção de sociedade do desempenho também como sociedade do cansaço, isto é, o tipo de ordenamento social no qual se experimenta o "cansaço solitário", que individualiza e isola. Han toma de empréstimo de Peter Handke a imagem de um cansaço que divide o indivíduo, que o fragmenta e o impede de agir.

\footnotetext{
"Esses cansaços consumiram como fogo nossa capacidade de falar, a alma!" eles são violência porque destroem qualquer comunidade, qualquer elemento comum, qualquer proximidade, sim, inclusive a própria linguagem: "aquele tipo de cansaço, calado, como teria de permanecer, forçava à violência. Essa, talvez, só se manifestava no olhar que desfigurava o outro" (Han, 2017d, p. 71-72).
}

A sociedade do cansaço, para Han, é marcada pela positividade, isto é, pela superação das várias formas de repressão que caracterizaram o nosso saber e o nosso fazer passados. A partir dessa mudança de paradigma, o autor postula inclusive uma releitura da psicanálise freudiana, não apenas em Sociedade do cansaço, mas também em Topologia da violência e muito mais em Agonia do Eros. O fato é que nessa sociedade da positividade, os dilemas políticos e sociais são internalizados e se põem como fonte das enfermidades características da nossa época.

Para nós, no entanto, interessa na obra de Han o capítulo Vita activa, dedicado evidentemente à Arendt em Sociedade do cansaço. O fato é que o filósofo se equivoca em sua interpretação por faltar com rigor na análise das distinções que Arendt faz entre as atividades humanas fundamentais. Porquanto essas distinções são parte do núcleo duro do pensamento arendtiano, posto que o método arendtiano da "análise conceitual" perpassa inequivocamente a distinção e a interseção entre os conceitos que fundam o seu marco teórico, o equívoco de Han não é circunstancial, mas conceitual, o que implica o desmoronamento da sua crítica à autora.

Depois de uma apresentação sucinta, mas bem colocada de $A$ condição humana, Han se afasta de Arendt porquanto, segundo a sua leitura, a descrição arendtiana do animal la- 
borans não corresponde à imagem do indivíduo da sociedade moderna. Dando a palavra ao filósofo, primeiro ele diz que "a explicação de Arendt para o triunfo do animal laborans não resiste a um teste comprobatório nas recentes evoluções sociais", e depois, que "as descrições do animal laborans de Arendt não correspondem às observações que podemos fazer na sociedade do desempenho de hoje" (Han, 2017d, p. 42-43). Nessa altura, fica evidente a crítica à descrição arendtiana da condição do indivíduo moderno "passivamente exposto aos processos biológicos da vida" (Han, 2017d, p. 41).

A nosso ver, no entanto, o autor não apresenta exaustivamente o que denota como "recentes evoluções sociais", nem tampouco as define, mas o mais importante vem depois. Han (2017d, p. 43) afirma que:

o animal laborans não abandona sua individualidade ou seu ego para entregar-se pelo trabalho a um processo de vida anônimo da espécie. A sociedade laboral individualizou-se numa sociedade de desempenho e numa sociedade ativa. $\mathrm{O}$ animal laborans pós-moderno é privado do seu ego ao ponto de quase dilacerar-se. Ele pode ser tudo menos passivo.

Grosso modo, o que Han assevera nessas linhas não parece contradizer diretamente o que Arendt defende em A condição humana. O mesmo pode se dizer quando, alguns parágrafos depois, ele diz também que "a sociedade do trabalho e a sociedade do desempenho não são uma sociedade livre" (Han, 2017d, p. 46). O que Han parece não entender é que trata das mesmas questões de Arendt, mas se mantendo num terreno diferente do dela, ou seja, como já acenamos, ele evita pensar a política no seu sentido próprio. O seu erro, portanto, é querer interpretar o discurso arendtiano a partir da própria perspectiva e não do ponto de vista e das preocupações da autora. Mas será possível interpretar o pensamento arendtiano tirando suas categorias do quadro do pensamento político centrado na ação? No terreno político, e isso Han não reconhece, o seu indivíduo pósmoderno, depressivo e acometido pela Síndrome de Burnout, é tão passivo quanto o animal laborans de Arendt. Em outras palavras, até certo ponto, Han confirma o que pensa negar. 
Ele volta a se equivocar em outros momentos. Segundo o comentador, a conclusão do livro vai nessa direção:

o último capítulo da Vita Activa [A condição humana] de Hannah Arendt trata do triunfo do animal laborans. Frente a essa evolução social, Arendt não oferece nenhuma alternativa efetiva. Apenas constata, resignada, que a capacidade de agir fica restrita a poucos. Depois, nas últimas páginas do livro, ela conjura diretamente o pensar (Han, 2017d, p. 48).

Essa afirmação se agrava quando a relacionamos ao que ele diz pouco depois: "não a vida ativa, mas só a vida contemplativa é que torna o homem naquilo que ele deve ser (...) Por volta do final do seu tratado Vita activa, sem querer, Arendt acaba falando a linguagem da vida contemplativa" (Han, 2017d, p. 49-50).

É necessário aqui fazermos algumas colocações. Primeiro, nos moldes propostos pela autora, a distinção entre a vita activa e a vita contemplativa é carregada de preconceitos e dualidades legadas pela tradição, como, por exemplo, a ideia de que a última é pura passividade, enquanto a primeira cabe apenas aos destemidos homens que se aventuram na esfera pública. Assim, é fácil cair na armadilha tradicional e se equivocar na diferenciação destas esferas. Na teoria arendtiana, a síntese entre elas não é simples, mas também não se pode concebê-las completamente dissociadas, pois, o mesmo homem que pensa, quer e julga é o agente que constrói a esfera pública (Villa, 2006, p. 19). Isto nos leva ainda para outro ponto: considerar que em geral não existe, em Arendt, a antinomia que separa os atores públicos daqueles pouco escolhidos para a atividade puramente espiritual. O filósofo, "um homem como você e eu" (Arendt, 2014b, p. 28), não é um escolhido, um privilegiado "amigo dos deuses", pois a capacidade de refletir sobre as próprias experiências não é uma prerrogativa de poucos. Tampouco existe o agente absoluto, pois a faculdade de iniciar processos, não é exclusividade de alguns, como Han parece querer interpretar, mas uma faculdade constitutiva que distingue os homens qua homens. Do mesmo modo, é inconcebível defender o abismo entre o homem que atua no espaço comum daquele que pensa, quer e julga, porque não há vita activa que não dialogue 
com as atividades do espírito (Arendt, 2005, p. 175-176). Isso pode ser comprovado pelo fato de que, se a preocupação com a ação dos homens é o centro da teoria política arendtiana, a preocupação com o pensamento, enquanto atividade espiritual mais radical, está igualmente disseminada pelo corpus teórico da autora. ${ }^{49}$ Assim, a capacidade de agir, distintivo da vita activa, está tão presente em todos os homens quanto o pensamento, predicativo da vita contemplativa. Do mesmo modo, a inação e o não-pensar também são possibilidades sempre presentes para todos. ${ }^{50}$

Outra interrogação a se colocar, mas que está ausente em Han, é se Arendt alcança os objetivos anunciados no início do texto, posto que a justificativa da obra está clara desde o Prólogo. Para tanto, seria o caso de dois questionamentos básicos no que se refere à interpretação filosófica: primeiro, perguntar pelo problema que, de fato, é posto; segundo - igualmente imprescindível -, inquirir pela sua formulação. Sem tentar aqui responder exaustivamente a isto, dizemos apenas que Arendt se mantém nos limites da proposta de "pensar o que estamos fazendo" (Arendt, 2014a, p. 6), e que não se mostra "resignada" nas últimas páginas do livro, mas termina, coerentemente, pondo as bases para uma outra face da mesma reflexão. Seu objetivo, com a exposição do pensamento no final do capítulo sobre a vitória do animal laborans, é de analisar que até que ponto, sob condições de massificação e de alienação do mundo, o pensar, enquanto pura atividade, não seria ameaçado. Não é um questionamento resignado ou fora de ordem, já que a experiência do totalitarismo e os elementos protototalitários que formam as bases da nossa sociedade se ancoram na prerrogativa de que, sob condições de alienação, isolamento e ideologia, é mais fácil agir do que pensar, e apenas aqueles que o conseguem mantêm intacta a capacidade política par excellence de julgar. ${ }^{51}$ Em outras palavras, recorda que justamente a atividade de pensar ainda é possível, e está mais presente nos

$49 \quad$ Fica evidenciado, por exemplo, nos trabalhos de Bernstein (2006), Heuer (2005) e Pansera (2007).

$50 \quad$ Cf. Castelo Branco e Rocha (2016).

$51 \quad$ Cf. Aguiar, 2012. 
lugares nos quais os homens vivam em condições de liberdade política. Infelizmente, nenhuma outra capacidade humana é tão vulnerável. A liberdade política é o horizonte para a ação e para o pensamento, e porquanto toda filosofia política pressupõe, ao menos implicitamente, uma antropologia filosófica, o pensamento de Arendt se funda, ao fim e ao cabo, no homem agente que só pode ser compreendido se tomado também como ser capaz de pensar, querer e julgar. Arendt, no fim, não nos faz retornar à contemplação, como diz Han, mas nos abre à reflexão sobre a vida do espírito.

\section{Considerações finais}

Começamos essa pesquisa com um duplo objetivo, ou um escopo que nos demanda lidar com duas questões, concomitantemente. Por um lado, cabia-nos retomar alguns elementos das condições do homem e da sociedade moderna na obra A condição humana e, por outro, ressaltar os equívocos que, a nosso ver, marcam a interpretação de Byung-Chun Han. Porquanto não se trata de uma análise da obra de Arendt, mas de responder às questões levantadas a partir da leitura da Sociedade do cansaço de Han, nos concentramos nas últimas seções de A condição humana.

Arendt apresenta a vitória do animal laborans, o que só é possível numa sociedade de empregados e de consumidores. Dito de outro modo, o homem só pode se compreender como animal trabalhador se inserido num mecanismo social de valorização absoluta do trabalho como a atividade par excellence, em cuja lógica ele mesmo se enxerga como função e não como sujeito. No que tange às preocupações da autora, isso significa também que esse indivíduo se perde no fluxo ininterrupto de suas necessidades vitais, nos processos ditados pelo próprio metabolismo. O homem se volta, então, àquilo que é mais individual: a própria vida e, nesse movimento, abandona a esfera pública e esvazia a política.

Enquanto Arendt se mantém nos limites de uma teoria política cujo eixo é a ação, Han se dedica a uma análise que 
se espraia por temas de filosofia, antropologia cultural, história, sociologia e psicanálise, e à base de sua reflexão, ele põe a passagem de uma sociedade repressiva àquela de desempenho. Nesta sociedade, Han (20171a, p. 75) toma o indivíduo no seu estado de depressão e acometido pela Síndrome de Burnout, "consequência patológica de uma autoexploração voluntária". $\mathrm{O}$ problema nasce quando Han contrapõe um sujeito às voltas com as exigências da "maximização do desempenho" (Han, 2017a, p. 262) ao animal laborans arendtiano descrito pela autora a partir também da sua incapacidade de agir. Ele parece não se dar conta de que Arendt sempre pensa a ação política e que a sua crítica só faria sentido de fato se fosse possível trazer os argumentos arendtianos ao domínio meramente social.

Como conclusão, queremos retomar as palavras de Arendt (2014a, p. 404) quando lembra que "não é preciso dizer que isso [a vitória do animal laborans] não significa que o homem moderno tenha perdido suas capacidades ou esteja a ponto de perdê-las". Antes o contrário, "pois se as várias atividades no interior da vita activa não podem ser submetidas a nenhum outro teste senão a experiência de estar ativo, a nenhuma outra medida senão o alcance da pura atividade, a atividade de pensar como tal bem que poderia superar a todas elas. Quem quer que tenha alguma experiência nessa matéria saberá quão correto estava Catão quando disse: “(...) - Nunca se está mais ativo que quando nada se faz, nunca se está menos só que quando se está consigo mesmo" (Arendt, 2014a, p. 406). O homem moderno não está condenado a existir apenas como animal laborans, mesmo que a Realpolitk e os eventos políticos catastróficos do século XX tenham suprimido o espaço público, mas, a partir da natalidade, sempre está predisposto a começar algo novo. Dito de outro modo, Arendt finda por nos convidar, em 1958, a começar a pensar outra saída para superar o atual estágio de inação do indivíduo moderno. Tivemos que esperar até a década de 70 pela obra $A$ Vida do espírito, que parcialmente retoma a mesma questão, sob outro enfoque. 


\section{Referências}

AGUIAR, O. Necessidade e liberdade em Hannah Arendt. Princípios, v. 19 , n. 32 (2012), p. 35-54.

ARENDT, H. Ação e a busca da felicidade. Rio de Janeiro: Bazar do Tempo, 2018.

ARENDT, H. A condição humana. Rio de Janeiro: Forense Unversitária, 2014a.

ARENDT, H. A vida do espírito. Rio de Janeiro: Civilização Brasileira, 2014b.

ARENDT, H. Diário Filosófico. Barcelona: Herder Editorial, 2006.

ARENDT, H. Homens em tempos sombrios. São Paulo: Companhia das Letras, 2017.

ARENDT, H. Origens do totalitarismo. São Paulo: Companhia das Letras, 2011a.

ARENDT, H. Sobre a revolução. São Paulo: Companhia das Letras, 2011b.

ARENDT, H. Trabalho, obra, ação. [Trad. de Adriano Correia]. Cadernos de Ética e Filosofia Política,v. 7, n. 2 (2005), p. 175-201.

BERNSTEIN, R. Arendt on thinking. In: VILLA, D. R. The Cambridge Companion to Hannah Arendt. Cambridge: Cambridge University Press, 2006, p. 277-192.

CASTELO BRANCO, J. Politique et dialogue. Réflexions inspirées par Eric Weil et Hannah Arendt. Meta: Research in Hermeneutics, Phenomenology, and Practical Philosophy, v. 10, n. 1 (2018), p. 55-76.

CASTELO BRANCO, J. - ROCHA, L. Medo, terror e inação segundo Hannah Arendt. Kínesis, v. 8, n. 19 (2016), p. 39-53.

CORREIA, A. Quem é o animal laborans de Hannah Arendt? Revista de Filosofia Aurora, v. 25, n. 37 (2013), p. 199-222.

DUARTE, A. Hannah Arendt e o pensamento político: a arte de distinguir e relacionar conceitos. Argumentos, v. 5, n. 9 (2013), p. 39-62.

DUARTE, A. Hannah Arendt e a Modernidade: esquecimento e redescoberta da política. Trans/Form/Ação, v. 24 (2001), p. 249-272.

ECCEL, D. Hannah Arendt e o problema da secularização na fundamentação de novos corpos políticos. Trans/Form/Ação, v. 41, n. 2 (2018), p. 119-136.

GENEL, K. Hannah Arendt. L'expérience de la liberté. Paris: Belin, 2016.

HEUER, W. "La imaginación es el prerrequisito del comprender" (Arendt): Sobre el puente entre pensamiento y el juzgamiento. 
Cadernos de Ética e Filosofia Política 7. São Paulo: Departamento de Filosofia da Universidade São Paulo, 2015, p. 37-51.

HEUER, W. - LIEBEL, V. Amor Mundi- atualidade e recepção da obra de Hannah Arendt. Estudos Ibero-Americanos, v. 43, n. 3 (2017), p. 500-503.

HURTADO, J. Por que há alguém em lugar de ninguém? O pensamento plural de Hannah Arendt. Princípios, v. 20, n. 33 (2013), p. 333-351.

LEIBOVICI, M. Hannah Arendt, une juive. Expérience politique et histoire. Paris: Desclée de Browner, 1998.

MÜLLER, M. A possibilidade de novos começos. Philósophos, v. 23, n. 1 (2018), p. 347-376.

HAN, B.-C. Topologia da violência. Vozes: Petrópolis, 2017a.

HAN, B.-C. Sociedade da transparência. Petrópolis: Vozes, 2017b.

HAN, B.-C. Agonia do Eros. Petrópolis: Vozes, 2017c.

HAN, B.-C. Sociedade do cansaço. Vozes: Petrópolis, 2017d.

HAN, B.-C. Psicopolítica. Herder: Barcelona, 2014.

PANSERA, M. Il significato ético delpensare.B@belonline/prite. N. 3 (2007), p. 95-106.

WEIL, E. Philosophie politique. Paris: Vrin, 1996.

YOUNG-BRUEHL, E. Por amor ao mundo. Rio de Janeiro: RelumeDuramá, 1997. 